Marvin J. Taylor

\title{
“I'LL BE YOUR MIRROR, REFLECT WHAT YOU ARE": POSTMODERN DOCUMENTATION AND THE DOWNTOWN NEW YORK SCENE FROM 1975 TO THE PRESENT
}

AT FIRST GLANCE, the Velvet Underground, whose haunting ballad "I'll Be Your Mirror, Reflect What You Are" provides my title, may not appear to have anything to do with authorization or with libraries (other than some library collections may have their recordings in the media center). ${ }^{1}$ And yet, the Velvet Underground, and "I'll Be Your Mirror" in particular, suggests a model for conceptualizing the process of canon building, the accreditation of literary figures and movements, and the role libraries play in both. I realize this is a peculiar statement, but there are several ways in which it is true. The Velvet Underground, with Lou Reed as its unsurpassed lead singer and songwriter, founded outsider music. This Lower East Side band, linked to Andy Warhol's Factory where it staged multimedia performances, was one of the most important precursors of the Downtown New York scene. Outsider art, outsider literature, and much that we now understand about the politics of being "inside" or "outside" are reflected in the work of the Velvet Underground. I'd like to frame some thoughts about the development of a postwar American canon of writers by looking at how libraries collect cultural materials. I would like to pose the following questions: What role do libraries play in determining what enters the

1. The Velvet Underground, The Best of the Velvet Underground, PolyGram Records, Inc., 1989.

(C) Copyright 2002. Marvin J. Taylor. All Rights Reserved. 
canon? How do libraries determine what aspects of culture will be preserved for posterity? It is to the metaphor of the mirror in "I'll Be Your Mirror, Reflect What You Are"-the title so important to Downtown New York work that the photographer Nan Goldin used it for her recent Whitney retrospective-that I turn as a mode of examining the role of libraries. Further, I'd like to use the mirror to explore how the Downtown New York art scene, which grew out of the same cultural ferment that produced the Velvet Underground, complicates our understanding of canon development and of the process and possibility of documentation in library and archival work. Moreover, what I am really proposing is that we have an opportunity when we collect twentieth-century materials to investigate the process of collecting, the meaning of what we do and care about as librarians, archivists, and curators. It's not that the same or similar kinds of structures don't apply to collecting earlier materials, but with contemporary materials we see more easily how our roles fit into the large social and historical patterns of collecting and authorization.

Boldly to generalize, the prevailing image of the library among the general public (and perhaps, actually, among librarians) is that libraries are repositories for our cultural heritage-a mirror held up to reality, the reflection being an accurate accumulation of documents from which we can reconstruct history. ${ }^{2}$ But are libraries, even when they attempt to collect comprehensively, really a mirror for culture? Can they reflect "what things are?" Do they preserve the documents that can explain how a culture looked? Do the materials in libraries really allow researchers to understand what it was like to live in a period? Or

2. In reality, there are probably two competing images of libraries: the connoisseurship model and the documentation model. Much work of the past 20 in culture studies has shown the implicit political, racial, gender, and sexual dynamics of connoisseurship to be very complicated and problematic as a sustainable model for collecting. I would hasten to note that my critique of the documentation model, which I believe superior to the connoisseurship model, is not meant in any way as an attack on documentation. Rather, it is intended to provide a more sophisticated understanding of how we can build collections within the documentation model. 
does the act of bringing something into a library alter the original documents so that their historical context is no longer visible? If so, how do libraries affect these materials?

As I've tried to collect the Downtown New York scene, these questions have become central to my thinking about how we build comprehensive collections. The Downtown Collection at New York University's Fales Library is the largest collection of printed and archival materials related to the Downtown New York scene anywhere. Currently, the Downtown Collection contains some 8,000 printed items, including monographs, more than three hundred periodical titles, 'zines, and other print publications. The archival holdings now number nearly 3,000 linear feet of material and include the papers of Ron Kolm, a central organizer and promoter of Downtown work; the archive of the Judson Memorial Church, a major center for avant-garde performance, theater, art, and dance dating back to the early 1960s; the archive of Between C\&D, the influential literary magazine of the East Village during the 1980s, coedited by Joel Rose and Catherine Texier; the archive of Serpent's Tail/High Risk Books, the important publishing house for Downtown works headed by Ira Silverberg; the papers of David Wojnarowicz, the noted artist, writer, performance artist, and photographer; the papers of Dennis Cooper, the poet, novelist, and editor; and the papers of many other writers and artists. The nature of these materials, their content, format, the vicissitudes of their production, and their relation to the Downtown scene that produced them have caused me to question some of our most commonly held assumptions about libraries and archives. The Downtown Collection raises questions about how libraries collect, about their role as preservers of culture, and about even the possibility of their providing organized knowledge. I'd like to explore how Downtown works of art, which question the structures of society-that is, the available discourses by which we describe things-question the library as a system that does 
violence through categorization of materials that do not uphold the same philosophical, political, and cultural outlook as those forces that created our libraries.

$* * *$

Beginning in the mid-1970s, a distinctively new attitude toward artistic production surfaced in Downtown New York. It was not a new aesthetic, not a new style, and not a unified movement but, rather, an attitude toward the possibility of art and the production of art that, though for the most part unformulated, was shared by a wide range of writers, artists, performers, musicians, filmmakers, and video artists who moved to the relatively inexpensive lofts and tenements of Soho and the Lower East Side. Influenced by the Beats, the New York School, Dada, Pop Art, Punk, Hippies, Marxists, and Anarchists, Downtown New York artists began to push the limits of traditional categories of art. Artists were also writers, writers were developing performance pieces, performers were incorporating videos into their work, and everyone was in a band. Along with the profound disruption of artistic specialization, Downtown works themselves undermined the traditions of art, music, performance, and writing at the most basic structural levels. Rather than overthrow traditional forms and establish a new movement, Downtown work sought to undermine from within the traditional structures of artistic media and the culture that had grown up around them.

Robert Siegle, the first academic to write about the Downtown scene, finds a central insurgency against the structures of culture in Downtown works. In his book Suburban Ambush: Downtown Writing and the Fiction of Insurgency, Siegle writes:

It is, then, an insurgency, but not one that expects to break free of some kind of specific corrupt institution. It is an insurgency 
against the silence of institutions, the muteness of the ideology of form, the unspoken violence of normalization. But it does not expect of itself the pure voice of the Other-it knows its own language is divided against itself, its every move a contradiction that marks the position of the speaking subject at the end of the twentieth century. ${ }^{3}$

Siegle describes Downtown writing as quintessentially postmodern in its approach to the "silence of institutions" and to the "position of the speaking subject"; that is, rather than seeing Downtown writing as something that attempts to overthrow institutions or to define a speaking subject that is universal and nonpositional, Downtown writing is about understanding how the discourse of institutions constructs who we are, and then uses that knowledge to complicate cultural discourse. Or as Siegle says:

Downtown writing seeks not liberation but liberty, real rather than full sensation, tactical critique rather than strategic game plan. It opens space-mentally, psychologically, semioticallywhere simulation, repression, and convention have converged to predetermine our Being. It shakes up reified relations-roles, genders, social structures-so that at least momentarily experiences of various sorts of Other might take place before the great culture machine swallows it up again. . [D]owntown writing persists in a sort of hit-and-run guerrilla action. ${ }^{4}$

Without assimilating into the traditional art scene, Downtown artists mounted a full-scale assault on the structures of society that had led to grinding poverty, homelessness, the Vietnam War, nuclear power, misogyny, racism, homophobia, and a host of other problems. Downtown artists were profoundly aware of the failure of modernist revolutions, but not willing to abandon the possibility of a better world. They

3. Robert Siegle, Suburban Ambush: Downtown Writing and the Fiction of Insurgency (Baltimore: Johns Hopkins University Press, 1989), 4.

4. Ibid., 3 . 
began to explore the cracks and fissures where human experience, the actual events of everyday life, undermines the oppressive, prescriptive structures of society. Hoping to kick culture-both in the sense of forcing it to change and, possibly, in the sense of giving up the stifling, prescriptive structures that are so addictive-Downtown art exploded traditional forms of art, exposing them as nothing more than cultural constructs. Verbo-visual writing, appropriation art, performance art, graffiti painting, Xerox art, 'zines, small magazines, self-publishing, outsider galleries, mail art, and a host of other transgressions abounded Downtown and dramatically changed how we think about the production of artistic work.

It is important to understand that Downtown artists are not held together as a movement; there is not one unified Downtown aesthetic, nor are there easily definable genres. Downtown works don't fall into the usual subject categories. What Downtown works do share is, as Siegle says:

a desire to use art in refabricating a basis for individuality in the face of our sharpened sense of the structural determination of our lives. That basis will not look like a Victorian self or a modernist narrative. Far from being defeated by contradictions, these postmoderns take from it the cue for an alternative logic. Far from being rendered hopeless by the seemingly inevitable drift of (inter)national politics, they borrow from disinformation the ironic habitation of familiar forms for crosspurposes. Far from being paralyzed by the anxiety of past master's influence, they appropriate them for commentary on classic motifs (such as mastery, originality, autonomy, representation) and art-world structures (such as publishing houses, galleries, museums, and criticism). Far from feeling compromised by the investment economics of art, they turn the art market into a microcosm of consumer capitalism. ${ }^{5}$ 
So what does all of this have to do with the library? As I began to process the books, manuscripts, and other materials we were acquiring as a part of the Downtown Collection, I began to experience problems. Downtown works, by their very nature, did not fit into the neatly defined categories the library had established, did not follow the same rigid adherence to authorship, did not even come from acknowledged publishers or suppliers of materials with whom our accounting office was comfortable dealing. I began to see that the same kinds of disruptions Downtown works effected outside the library were occurring as I brought these materials into a major research collection. Now, the systems of the library come under the same scrutiny as the larger structures of society.

A few examples of the problems we encountered while processing the Downtown Collection point to an overall normalizing function libraries perform when they process materials. One of the most obvious problems is that of classification. David Wojnarowicz was primarily known as an artist and photographer, though he worked in nearly every artistic medium. His papers include more than 5,000 negatives, films, punk songs (both lyrics and performances), performance pieces, poems, prose, diaries, letters, found objects, and a host of other materials. Wojnarowicz also had AIDS and his later writing reflects his experience of the disease, intercut with his experiences of child abuse, drug use, and prostitution. An avid illustrator of his own writing-in fact, the illustrations often appear within the manuscripts for his stories-Wojnarowicz created a text, Memories That Smell Like Gasoline. ${ }^{6}$ This haunting text about his life as a queer man contains descriptions of his battle with AIDS, but is much broader and depicts the life of an incredibly sensitive boy caught in the prescriptive nexus of structures such as sexuality, family, law, and gay life, none of which he 
fits into easily. With its Curious George-like illustrations, the book is a quintessential outsider piece and inherently "Downtown" in feel. When the Library of Congress catalogued the book, it applied entries for: "1. Wojnarowicz, David. 2. AIDS (Diseases)-Patients-United StatesBiography. 3. Artists-United States-Biography. 4. Gay men-United States-Biography. I. Title," and classified the book under RC607.A26W64 1992, that is, placing it among the medical books about AIDS. This act reduces Wojnarowicz's life and work to his illness. Wojnarowicz was keenly aware of how culture tried to limit him by labeling his work as simply "AIDS art." He was famous for going into bookstores and moving all of his books from the AIDS section to the general literature section - an act of overt activism against the cultural attempts to define him as an AIDS victim and thus to pigeonhole his very transgressive work. The overall effect of the classification is to say that Wojnarowicz is not a writer or an artist primarily but, instead, an AIDS patient. If he were thought of as an artist or a writer, he would be classified with art or with literature. ${ }^{7}$

A similar problem arises with Art Spiegelman's Maus: A Survivor's Tale. ${ }^{8}$ Spiegelman was not the first graphic novelist. The form was one that many Downtown writers explored, making a direct link between comix, television, and the future of fiction. Structurally, Maus is a conventional narrative that happens to be told as comix. It depicts the events of the Holocaust as told by a mouse to his son and in which the Nazis are depicted as cats. The popularity of Maus and its importance for the development of the graphic novel cannot be overestimated. It defined the American graphic novel. The Library of Congress, however, decided that it is not really a novel. Maus is classified as D810.J4 S643

\footnotetext{
7. There is a danger in classifying Wojnarowicz's work in literature, too. Such a classification could universalize his experience, undermining the specifics of his life, which are all important to his work. The risk of universalization seems less egregious than the limitations placed on him by defining him as primarily an AIDS patient.

8. Art Spiegelman, Maus: A Survivor's Tale (New York: Pantheon Books, 1986).
} 
1986, placing it in the history classification, negating it as art and literature. The system, unable to accommodate the graphic novel, treats it, instead, as history rather than art or fiction. This act undermines the important breakthrough that makes Maus a very special work.

A third instance of this kind of regularization by libraries indicates a larger pattern by which materials with sexual content are discredited. Dennis Cooper's novel Try is widely acclaimed as one of the most important novels of the 1980s. ${ }^{9}$ This postmodern narrative explores the nature of male-male desire at the limits of representation. Focusing on a group of Los Angeles high school boys, the novel depicts the culture of drugs, sex, and violence that lurks behind the well-manicured suburban LA lawns. Minimalist in style, the text has a haunting, sterile tone that describes examples of violence, gay sex, sexual abuse, and heroin addiction. This is not a text about "Gay men-fiction," although the characters are men who have sex with each other. Neither is it a text that should receive the heading "Erotic stories." The novel is not meant to arouse you with its scenes of sexual violence. (If it does, it is in the way that Genet's Querelle arouses. It is not soft-core pornography.) Cooper's novel is completely misrepresented by the heading "Erotic stories." Further, it is degraded. Lacking a more sophisticated terminology for Cooper's achievement, the library uses "erotic stories" to describe this work. This serves most readers to turn away from Try as a serious novel. Cooper's work uses extreme expressions of sex and sexuality to examine the nature of desire. Library organization, like that of the culture at large, is uncomfortable with these expressions. This uneasiness is reflected in the lack of sufficient terms for sexuality. Of course, the system can and does undo itself at times. One of Cooper's other books was given the subject heading "teenage boys- 
fiction." I can just imagine a young librarian suggesting this book to a 14-year-old boy, having found it after doing a subject search. In this case, the erroneous (or mischievous) application of a subject heading contradicts the system of control.

Although not technically a "Downtown" book, Judith Butler's Gender Trouble: Feminism and the Subversion of Identity serves as a touchstone for many younger Downtown writers and artists. ${ }^{10}$ A cornerstone for queer theory, this text, too, suffers from similar misinterpretation by the LC subject headings. Classed in HQ1154.B88 1989 as though it were a sociological text, the book is really a philosophical treatise. The subject headings applied to it attempt to rectify this by giving the book "1. Feminism-Philosophy" as a heading but then go further and undermine their intent, supplying "2. Sex role. 3. Sex differences (Psychology) 4. Identity (Psychology) 5. Femininity (Psychology)" (Butler iv).

The LCSH are so strongly inflected by the distinction between humanities and social sciences that Butler's book presents a problem. Having no adequate terminology for her work, the subject headings limit the very intent of the book by placing Butler's argument within the context of psychology. Although it is true that Butler examines the work of many psychologists who explore gender, her work is not about psychological aspects of feminism, identity, or femininity. It is about the structures of culture that produce the possibility of understanding femininity. This subtle and central idea of the text is undermined by the subject headings that try to fit the book into a discourse, that of psychology, which the book is critiquing.

A different problem arose as we were processing the books and papers of Ron Kolm, one of the mainstays of the Downtown scene. Kolm amassed a huge collection of printed materials about Downtown 
writing. Nearly half of the material did not have online catalogue records, presumably indicating that other institutions do not hold copies of these outsider publications. The same was true for the more than 300 periodical titles. A few of the better-known writers and artists in the collection had online records. As I looked over the materials and spoke with Kolm and other members of the Downtown scene, I became aware of the incredible importance of many of the writers whose works were not documented in any library. (It reassured me that we were doing the right thing by collecting them.) I feared, however, that these lesser-known writers, many of whom were friends of people such as Kathy Acker, Gary Indiana, Spalding Gray, Lynne Tillman, and others would simply be lost in the online catalogue and forgotten. In consultation with our cataloguing department, we created a special subject heading of "Downtown writers" and placed it on all materials added to the Downtown Collection. In this way, lesser-known authors will have at least one chance of being remembered and found by researchers.

We made similar decisions that did not follow common practice when processing archival materials in Kolm's papers. Kolm was a natural archivist. When I first visited his apartment in Long Island City, he had an entire room of a two-bedroom apartment full of boxes of Downtown materials. (He and his family were living in the other three rooms.) Along with the printed materials, Kolm had some 20 boxes of archival materials, including correspondence, manuscripts, photos, art, posters, ephemera, videos, sound recordings, and thousands of announcements for openings, readings, and performances. Most of the material was easy to process, but the announcements, which are usually roughly sorted into folders with little organization, presented a special problem. Announcements were particularly important for reconstructing the Downtown scene. Many Downtown works are intensely collaborative. Readings, performance pieces, gallery shows were often joint ventures and provided important meetings of the 
Downtown community. By looking at the huge number of announcements Ron had preserved, I was able to begin to chart links among artists and writers, to locate the spaces where these various groups performed, and to begin to understand the culture that developed in Soho and the East Village. Rather than following a traditional method of organization, the librarian who processed these announcements sorted them by person, if it was a one-person show, and by place, if there were two or more. Readings, gallery shows, concerts, punk band announcements (including a ping-pong ball announcement for CBGB's) all received special attention. In many instances, Kolm's flyer may be the only artifact from the reading, the performer, and often the venue that survives. (To give you some idea of what I mean, in the mid-1980s, more than 200 galleries were in a twelve-square-block area of the Lower East Side. Today, there are only two and neither was there during the height of the East Village scene.) Had we followed standard practices, we would have rendered virtually unusable this wellspring of information about the day-to-day activities of the scene.

Finally, precious little Downtown material was published through major publishers. Small publishers and self-published works abounded. Tracking this material is very difficult. There are no vendors who handle Downtown works comprehensively, though Printed Matter, the Soho artist's bookshop, has a wide selection. Downtown work falls through all the cracks of traditional publishing and thus does not automatically get into libraries. Many librarians are expert at finding this kind of material; my point is merely to say that Downtown writers chose not to send texts to mainstream publishers, largely to maintain their edge. It is also true that most of their work is so transgressive in terms of style, format, genre, content, or other elements of expression that most mainstream houses would not consider publishing it. Libraries collude to a large extent with publishers to support what might be thought of as the academic/publishing/ 
library complex. ${ }^{11}$ If your work exists outside this network, chances are it will not be preserved for future generations to view. We may have plenty of cookbooks, romances, and mysteries-all of which I think are important and essential for us to collect and preserve-but precious few chapbooks of experimental poets, flipbooks by naïve comix artists, or edgy fiction with graphic sexual content.

Why is it, then, that libraries limit materials through classification, application of subject headings, genres, and author's intent? Why do we not process some materials as fully as others, privileging the correspondence, manuscripts, diaries, and other written documents of an author over other archival materials? Why do we tend to trust publications by established publishers rather than seriously evaluate small or selfpublished works? The usual litany of answers includes the following: It costs too much, publishers weed out bad materials, scholars are primarily interested in academic materials, or, in archival terms, in biographical and literary materials about a writer or artist's development. All of these answers are laden with value assumptions with which the library is complicit. Such compliance, even if benign, does violence against those materials that question the processes of validation in our culture-and, in fact, all materials, even those more readily acceptable to mainstream culture. We in libraries can be the greatest enemies of the preservation of culture when we believe we are documenting ideas for the future but do not knowingly select materials that lie outside the academic/publishing/ library complex.

By acquiring and cataloguing Downtown materials, I began to see the modern library as just another discourse of culture, one that constructs authors, fixes subject positions (and subjects), defines movements, solidifies

11. This term is a reformulation of the "military/industrial complex," which was perhaps the first widely known example of how discourses of society collude with one another to structure how we think. It was certainly one that was accessible to many Downtown artists and probably helped shape their larger understanding of the ways in which discourse structures our lives. 
genres, validates publishers, justifies periods, privileges heteronormative relations. In short, the library is one of the major linchpins in maintaining the complex weave of discourses that produces culture and constrains the individual. Downtown works, however, have opened for me within the library the same kind of space "mentally, psychologically, semiotically" that Siegle sees they open up in culture at large. These works "shake up" our common assumptions about "roles, genders, social structures," as Siegle says, "so that at least momentarily experiences of various sorts of Other might take place before the great culture machine swallows it up again." In this case, Downtown works undermine the stability of the discourse of the library, which, with its classification schemes, processing rituals, and economic modes for assessing historical or literary value, stands as the cultural system par excellence that reifies, legislates, represses, normalizes, and creates the possibility of what can be known, who can know it, and how it will be preserved.

$* * *$

I realize that my argument is beginning to sound like one made by Michel Foucault, whose work underpins much of postmodern thought and most of the cultural criticism that has swept through academia in the past 20 years. Foucault's work is related closely to the concerns of Downtown artists; much Downtown work was being formulated concurrently with his. Curiously, for someone who critiqued the effects on the individual of most of the major structures of society, from the language of science and linguistics to law and sexuality, Foucault remained silent about the library as yet another discourse of society. ${ }^{12}$ And yet, as I hope the examples from the Downtown collection show, it is clear that we are involved in violence against, and the silencing of, materials when we integrate cultural materials into our collections. 
For Foucault, there is no overarching knowledge that is not linked specifically to the discourses of the time in which that knowledge was first available. In other words, the structure of our understanding of anything is necessarily caught up in time; there is no a priori, that is to say, something that exists before or outside time, only ever what Foucault paradoxically calls an "historical a priori." 13 Within any given historical period, then, and under the same governing rules that inform the "historical a priori," there is an "archive" that culture produces. For Foucault, the "archive" is not the sum total of the experiences of individuals in a given historical period as preserved through the memory of the culture, but only ever a subset of its "historical a priori," the peculiar subset of experiences that can be expressed within the constraints of that culture. ${ }^{14}$ The "archive," thus, is only the record of those experiences "that appear by virtue of a whole set of relations that are peculiar to the discursive level" of that culture. For Foucault, this "archive" is never mimetic of culture, but only a product of the possibilities created by the interwoven cultural discourses. It will come as no surprise that Foucault believes that "the archive of a society, a culture, or a civilization cannot be described exhaustively." ${ }^{15}$ At the same time, however, he believes that "its presence is unavoidable. It emerges in fragments, regions, and levels, more fully, no doubt, and with greater sharpness, the greater the time that separates us from it: at most, were it not for the rarity of the documents, the greater the chronological distance would be necessary to analyze it."16

I do not agree with Foucault. I believe he is right that the "archive" cannot be described completely. (Not all experiences are written down; memory is a cherished and fragile medium. Moreover, language itself never can express all the things the body knows-the ineffable, animal

13. Michel Foucault, "The Discourse on Knowledge," in The Archaeology of Knowledge and the Discourse on Language (New York: Pantheon Books, 1972), 127.

14. Ibid., 129.

15. Michel Foucault, "The Discourse on Knowledge," in The Archaeology of Knowledge and the Discourse on Language (New York: Pantheon Books, 1972), 130.

16. Ibid. 
truths we each understand at some level prior to and beyond the verbal.) This does not eliminate the possibility of attempting to preserve more materials to make a better reconstruction of the "archive" possible. By my engagement with the current Downtown scene, I have a special opportunity to preserve more of the "archive" of that scene than a library would normally preserve. In her useful and concise volume, Queer Theory: An Introduction, Annamarie Jagose notes that "Gilles Deleuze, in reading Foucault, talks about the new archivist who sees effects neither in a vertical hierarchy of propositions stacked on top of one another, nor in clean horizontal relationships between phrases that seem to respond to one another. Instead the new archivist 'will remain mobile, skimming along in a kind of diagonal line that allows him [sic] to read what could not be apprehended before.'"17 Following Deleuze's reasoning, I believe it is possible for libraries to collect consciously. If the librarians and archivists who have responsibility for preserving the documents of our culture approach the process of documentation knowing that, possibly, we can never fully document a culture, then we make very different decisions about what we collect and how we preserve it. If Foucault is right, we need to preserve as large a body of documents and artifacts as we can so that with the passage of time the documents of our culture, now rare themselves, will be available for study.

Foucault presents a curious problem for me. At the end of the passage, he begins to sound as though the "archive" is something that exists and can be known at some indeterminate point in the future; if not in its "totality," at least the "fragments" and "levels" of understanding begin to accumulate to make up something that begins to approach an understanding of the "archive." I suggest that Foucault should have looked to the libraries, for it is within their walls that much-but, importantly,

17. Annamarie Jagose, Queer Theory: An Introduction (New York: New York University Press, 1996). See also, Gilles Deleuze, Foucault, trans. and ed. Seàn. For. Paul Bovè (Minneapolis: University of Minneapolis Press, 1988), quoted in Jennifer Terry, "Theorizing Deviant Historiography," differences 3, no. 2 (1991): 56-57. 
not all-of the "archive" will be determined. It is by what we in libraries collect that a large portion of the "archive" will be made knowable. But we cannot just continue to collect in the ways we always have and preserve materials that can document the archive of our "historical $a$ priori." If we had continued to collect in the usual manner for the Fales Library, the Downtown scene would only be known by those few writers and artists who broke through into the mainstream of publishing-those canonized through overlapping criteria established by the media, critics, and other people with cultural power. Much Downtown material has already disappeared; much more would have vanished if we had not begun to collect it when we did-it would only have taken a fire at Ron Kolm's apartment and a huge portion of the Downtown scene would have been lost forever.

I'd like to propose an alternative to Foucault's rather bleak prognosis for documenting the "archive." I'd like specifically to think about his idea that the "archive" "emerges in fragments, regions, and levels," for it is here that we have something to use as a means by which to more thoroughly document the "archive." Oddly enough, we return to the mirror-more specifically, to Jacques Lacan's conception of the mirror stage of psychological development. In his essay, "The Mirror Stage as Formative of the Function of the I as Revealed in Psychoanalytic Experience," Lacan explains the moment of recognition of the subject (a baby), when standing before the mirror he or she first understands that the reflection in the mirror is his or her self. Or, as Lacan puts it: "The mirror stage is a drama whose internal thrust is precipitated from insufficiency to anticipation - and which manufactures for the subject, caught up in the line of special identification, the succession of phantasies that extends from a fragmented body-image to a form of its totality." ${ }^{18}$ What is important for us here is that the child's actual vision in the mirror is not 
one that is complete; it is not a totality-for obvious reasons: The child does not have sufficient motor control to stand steadily in front of the mirror at the age when the mirror stage occurs. Rather, the mirror stage exemplifies the moment when, based on the anticipation that something actually exists out there, that is, his or her self, the child projects its own identity, his or her own I, or, in the English translations of Freud, his or her ego. The image in the mirror need not be absolutely accurate, sharp, and clear for the child to understand that he or she exists.

It is precisely this Lacanian mirror that we can use as a model for documenting cultures. If we collect, as comprehensively as possible, the multiple and varying fragments, shades, levels-the fuzzy images of the areas of culture that our collections encompass, then we are truly collecting something that will have lasting value beyond the highly regimented, approved discourses that culture promotes. Another way to think about this might be to compare how one might conventionally collect the Downtown scene to how I have actually chosen to collect it. The conventional approach would have been to develop a list of the very best authors, as noted by the mainstream press, who wrote Downtown, and to put together sets of their first editions. This would give one prescriptive view of the Downtown scene. If I chose to go beyond these authors and look at who Downtown writers felt were important, I could create a collection that could serve both audiences. But to really begin to document the scene, I need to collect much more broadly. To document the interactions of a wide range of artists. To acquire books, papers, realia, ephemera, videos, sound recordings, posters, and varieties of materials that the Downtown scene seemed to have no end of fun producing.

By overlapping these various images of the Downtown scene, some no doubt fantastic, some projected, some politicized, some aesthetic, I have a better chance of documenting the Downtown scene. I have had to posit the identity of the scene. I have had to hold the mirror up to it, but I have not allowed myself to believe that I can reflect what the scene really is like. 
Rather than mimesis, I am positing the "archive" as a series of overlapping representations that I hope, in their interrelatedness, more accurately reflect the archive than any single one could have done. In this way, I can better attempt to know what the scene was like.

This approach is not without land mines. Foucault astutely notes the ways in which disciplines create individualities, "Disciplines constitute a system of control in the production of discourse, fixing its limits through the action of an identity taking the form of a permanent reactivation of the rules." ${ }^{19}$ When I posit the Downtown scene as something that exists, even if I posit it as a series of divergent and overlapping reflections of the events and personalities, I engage the larger systems of cultural discourse that reinforce the very possibility of identities and/or rules that govern them. The examples above of how libraries limit David Wojnarowicz's work to AIDS art and Dennis Cooper's novels to "Erotic stories" represent exactly this kind of control. Libraries limit the transgressive nature of Wojnarowicz's and Cooper's works by creating standard, library-defined identities for them, thus reactivating and reinforcing the traditional cultural rules that govern how these artists should behave rather than describing the works they have created. The library reactivates the rules of culture. It diminishes art that engages the experience of AIDS to something less than real art. It re-inscribes the notion that serious novels do not use sex and sexuality as the content from which to explore language and the possibility of representation.

If we cannot escape the possibility of reactivating these larger rules of culture, what should we do when attempting to document culture? I have taken my lead from Downtown works themselves. Downtown work engages in the processes of culture, but always with an understanding of how those processes work. As a librarian working in one of the major institutions that regulates culture, I need to act like one of the outsider

19. Michel Foucault, "The Discourse on Knowledge," 224. 
artists. Whenever there is a chance to critique the processes of the library, to perform a "hit-and-run guerrilla action," I do. In the end, Downtown work offers a different stance toward how we view our role in relation to the structures of culture. In addition to holding the mirror up to culture to reflect the various and conflicting images that may allow me to preserve a part of the "archive" of the Downtown scene, I have to also always be aware that I am not only looking into the mirror, but also-and most importantly-holding it up. 